\title{
Is it Time to Update the Definition of Political Participation?
}

Whiteley, P. (2012) Political Participation in Britain: The Decline and Revival of Civic Culture, Basingstoke: Palgrave Macmillan

According to Paul Whiteley's Political Participation in Britain, 'Britain is on the edge of being relegated from the premier league of being a 'Full Democracy' to the category of being a 'Flawed Democracy' alongside countries such as Italy, Slovakia and Mexico'. Whiteley's book is subtitled The Decline and Revival of Civic Culture (although there is much more on the decline, less on the revival), and for any scholar or politician concerned about British democracy, political participation, or civic culture it should be a keystone of their reading list.

It is a health check on British democracy, examining the relationship between political participation, civil society and democracy in Great Britain and looking at how behaviour has changed over the last 50 years. Whiteley concludes that British citizens are becoming increasingly disengaged from civil society, and that this is having a detrimental impact on the effectiveness of the British government, with grave consequences for the future sustainability of liberal democracy in Britain.

Through an extensive empirical examination, drawing on a vast array of data from multiple sources (including the British Election Study, the European Social Survey, the World Values Survey and the International Social Survey Program), Whiteley examines the essential components of British civil society: the attitudes and values of British citizens towards government, democracy and each other; 
political participation; engagement with political parties and other social and voluntary organisations; and the media.

British citizens are increasingly less likely to engage with political parties; partisanship has declined by $40 \%$ between 1964 and 2005, and Whiteley cites the hung Parliament in 2010 as evidence of the major shift in British politics caused by this trend. Social capital in Britain is in decline, as evidenced by falling membership in political and community organisations like trade unions, membership of which has fallen from $13 \mathrm{~m}$ in 1979 to $6.9 \mathrm{~m}$ in 2008 . Social trust is also in decline, with the proportion of Brits feeling that 'most people can be trusted' falling from $43 \%$ in 1981 to $30 \%$ in 2005 . The British are becoming less supportive of active government, and their confidence in the effectiveness of Parliament is deteriorating; on a $0-10$ scale, the mean score for Parliamentary effectiveness in the British Election Study for 2001 was 5.5, by 2010 this had fallen to 4.7 - given the events which rocked the British Parliament (such as the MPs expenses scandal) between these two studies, this is not a huge fall, but it is nonetheless a notable drop.

Participation is also down. In the 1980 s, $63 \%$ of people reported signing a petition, while only $40 \%$ reported doing so in 2002 . Some $12 \%$ said they had worked in or with a political party in the 1980s while only 3\% did so in 2002 . Finally, and for Whiteley most seriously, voting has also declined, with nine out of ten eligible voters turning out in 1950 compared with just over six out of ten doing so in 2010.

One of the unique components of this research is the empirical examination of the causal link between an engaged civil society and effective democratic government. Rather than merely noting the decline of civic engagement, 
Whiteley considers the consequences of this for British democracy. Using data from the World Bank, and focusing on measures of effective government largely relating to public service delivery and efficient policy making, he shows that there is a correlation between an engaged civil society and the effectiveness of a government.

Central to the argument is the assertion that political participation is in decline. Yet one of the weaknesses of this analysis is that Whiteley gives little attention to the conceptualisation of 'political participation'. He fails to consider the ways in which political participation in Britain has changed in recent years in response to societal and technological developments. From Almond and Verba in 1963 the starting point of Whiteley's comparative analysis - through Parry et al (1992) and Pattie et al (2004) - the other comparable studies which examined political participation and civic attitudes in Britain - to 2012, the definitions of political participation employed when examining British civil society have remained broadly similar. The concept has 'grown' somewhat as more aspects of political participation have been included and as the range of accepted targets of political behaviour has expanded, but many of the basic criteria which underpinned Almond and Verba's definition in 1963 have endured through to Whiteley's latest work.

As Verba et al pointed out in 1978 , there is of course no 'true' definition of political participation, but rather definitions have to be appropriately adopted so as to suit the research context. This definition is dependent upon the scholar's assessment of the purpose of political participation: is the purpose to change or influence government outcomes (Whiteley, 2012; Parry et al, 1992; Pattie et al, 2004; Verba et al 1978), to establish societal goals (Verba and Nie, 1972), to 
allocate social values (Easton, 1965), to change and/or establish the allocation of public goods (Booth and Seligson, 1978), or to engage in a process of managing co-existence with other individuals (Milbrath, 1965)? Given the wide range of arguments outlining the purpose of political participation, it is difficult to find a consensus on how political participation should be defined and quantified.

Drawing on decades of work in this field, it is possible to outline a series of criteria around which most conceptualisations of political participation are based. Different definitions can be assessed and compared based upon their choices regarding the following criteria $^{1}$ :

1. Active vs passive behaviour. Does the political participant have to act, or is it sufficient to passively hold certain values or attitudes? (Conge, 1988; Oldfield, 1996; Verba et al, 1978; Verba, 1967; Verba, Schlozman and Brady, 1995; Verba and Nie, 1972).

2. Individual vs group activity. Does political participation have to be carried out in a group or does individual political engagement aimed at influencing individual-level circumstances count? (Verba, 1967; Conge, 1988; Verba et al, 1978).

3. Instrumental vs symbolic activity. Must political participation be intended to achieve some tangible goal in the interest of (or of interest to) the participant, or does symbolic activity with no tangible goal count? (Verba and Nie, 1972; Verba, 1967; Scoff, 1975; Krueger, 2002).

\footnotetext{
1 - Conge (1988) used a similar format for outlining the criteria for defining political participation. This analysis uses the same style, but is more extensive.
} 
4. Voluntary vs mobilised or forced activity. Must political participation be voluntary, or can it be mobilised or forced by institutions and/or other people? (Verba et al, 1978; Verba, Schlozman and Brady, 1995).

5. Deliberate aims vs unintended consequences. Are the deliberate aims of the activity what makes something political participation or can the unintended consequences of a political nature identify an act as political participation? (Conge, 1988; Verba, 1967).

6. Legal/conventional activity vs illegal/unconventional activity. Is political participation limited to legal activity, or does illegal activity count? Do we focus on established, 'conventional' forms of behaviour or do we need to take account of 'unconventional' behaviour? (Verba et al, 1978; Verba and Nie, 1972; Marsh et al, 2007; Barnes et al, 1979; Salisbury, 1975; Van Laer and Van Aelst, 2010; Stockemer and Carbonetti, 2010).

7. Influence vs intent. Is something only political participation if it has a tangible influence its target, or is the intent of having influence sufficient? (Schonfeld, 1975; Verba and Nie, 1972).

8. State/government target vs general political actor target. Must political participation be targeted at the government or state, or does activity targeted at other entities or people count? (Verba and Nie, 1972; Marsh et al, 2007; Verba et al, 1995; Norris, 2002; Verba, 1967; Dahl, 1963; Oldfield, 1996; Conge, 1988).

9. Successful vs failed activity. Is something only political participation if it succeeds in achieving the intended outcome of the actor/s? (Verba, 1967). 
In developing their definition of political participation, Almond and Verba (1963) addressed four of these criteria. They argued that a citizen had to actively engage in certain behaviour (p.148), with the deliberate intent of influencing government (p.117), in order to be considered a political participant. They also argued that political participation is not limited to legal or conventional behaviour (p.148), and implied that a participant can act alone or as a part of a wider group or institution (p.148). Political participation, then, was defined as active behaviour, that can be individual or communal in nature, which is not limited to legal or conventional activity, and which is always targeted at the government; this definition, therefore, directly references the first, second, sixth and eighth criteria discussed above.

Thirty years later, Parry et al's (1992) definition of political participation differed little from The Civic Culture; their definition was only different on one of the four criteria considered - that of the target of political participation. Paradoxically, Parry et al clearly stated their agreement with Almond and Verba that the target of political participation is always the government (p.7), but they also implied recognition that political activity need not necessarily be aimed at the government, and that citizens may choose to interact with other institutions which influence governmental output (such as interest groups or the European Union) (p.40), or to lobby other individuals in order to mobilise them to vote (p.16). With one exception (that of voting in European Parliament elections) Parry et al did not measure either of these extra forms of political participation, so while in theory the target of political participation was expanded from that suggested by Almond and Verba (1963), in practice it was almost the same. 
The other criteria Parry et al (1992) considered are the same as those in The Civic Culture; they argued that political participation must be deliberate and active behaviour (p.39), and that this behaviour can be individual or communal, and need not be legal or 'conventional' (p.40, p.41). Despite a gap of thirty years, therefore, Parry et al's (1992) definition of political participation was barely different from Almond and Verba's (1963), and addresses the same four conceptual criteria.

Broadly, the same can be said of Pattie et al (2004). Pattie et al agreed that political participation has to be active behaviour and that the activity can be individual or communal in terms of both its scope and intended effect (p.3). They also argued that the action need not be legal (p.3). The differences in Pattie et al's (2004) definition come in the form of an expanded concept rather than a re-designed one; Pattie et al make clear that political participation must be voluntary behaviour and cannot be something forced or legally required (p.3), addressing the fourth criterion in the above list.

They also differed markedly from Parry et al (1992) and Almond and Verba (1963) by expanding the range of targets an individual or group can interact with beyond just the government to include the state generally and the services it provides (Pattie et al 2004, p.78). This conceptual expansion gave rise to what Pattie et al labelled 'micro-politics' - the output of the state at the level of people's daily lives through the delivery of services (p. 110). Political participants, therefore, can be considered as such if they choose to interact both with the mechanisms of government selection and policy-making, and the servicedelivery elements of the state such as schools and hospitals (p.110). The definition of political participation used in Pattie et al (2004), therefore, was 
largely the same as that used by Parry et al (1992) and Almond and Verba (1963), but with limited conceptual expansion.

The same is true of Whiteley's study. He agrees that political participation is active behaviour, and can be of an individual or communal nature with the intent of influencing individual or communal interests (p.34, p.36). He agrees with Pattie et al (2004) that all political participatory activities "have a common thread involving volunteering as, for ordinary citizens, they are unpaid" (p.34), and are ultimately targeted at influencing the delivery of state outcomes, whether in the form of government policy or state services (such as healthcare) (p.34). Whiteley agrees with Parry et al (1992) and Pattie et al (2004) that the relative power of the state in both the domestic and international spheres is in decline, and that consequently other targets of political activity are growing in prominence for citizens (such as the European Union or non-governmental organisations). Whiteley also argues that talking with other people to influence their political views is 'informal participation' (p.36), meaning that the targets of political participation include other political actors.

Finally, Whiteley addresses a criterion of political participation not mentioned by the previous studies (the third in the above list), and points out that participatory acts can be both instrumental (i.e. intended to produce a specific outcome) and symbolic (i.e. intended to demonstrate an opinion) in nature (p.34); he does not believe that favouring one or the other is a necessary step in identifying political participation.

Following his consideration of these criteria, Whiteley's stated definition of political participation is "activities such as voting, lobbying politicians, attending political meetings, joining protest rallies and being active in political parties. 
These activities... are all designed to directly or indirectly influence the policies and/or personnel of the state" (p.34). He measures political participation through the 2002 European Social Survey, which examined activities including voting, signing a petition, political consumerism, contacting a politician or government official, displaying campaign material, working in a voluntary organisation, donating money to a political organisation, taking part in a lawful public demonstration, working in a political party or community action group, or taking part in illegal protest activity (p.35).

While there are marginal differences between the definition employed by Whiteley and that used in the other three studies, there is nonetheless a common approach to defining political participation in all four works. Whiteley and Pattie et al (2004) offer conceptual expansions, but do not critique or reverse any of the choices made by Parry et al (1992) or Almond and Verba (1963). The general approach to defining political participation in these studies of British civil society can, therefore, be characterised along the lines of six of the criteria discussed in the above list. Political participation is always active behaviour (criterion 1), and can be engaged in by an individual or a group, with the aim of affecting individual or group concerns (criterion 2). It can be either instrumental or symbolic (criterion 3), must be voluntary (criterion 4), and can be legal or illegal (criterion 6). Finally, political participation is always targeted at the state or an entity responsible for discharging state responsibilities or services (criterion 8).

Of these six central characteristics, one in particular is problematic - the acceptable target of political participation. Linking the target of political participation to the state alone ignores the impact that significant societal 
change over the last fifty years has had on the distribution and relations of power in Britain and on the participatory opportunities that exist, which mean that there are potentially a much wider range of targets for political participants to interact with than just the state or state-related services.

There are two elements of this change in particular which have significant consequences for political behaviour to be considered: the growth and advancement of information and communication technology (particularly the Internet), and globalisation.

The Internet has had a huge impact on both the way in which people connect with each other and the way that they gather and share information (Dalton, 2009). It allows communication with little regard for geographical boundaries (so long as those places have Internet access), and significantly reduces the obstacles to communication presented by time and language restraints. In addition, Bennet (2008) points out that people now have the capacity through the Internet to produce digital media which can be more readily and rapidly accessed than any other type of media. Theocharis (2012) highlights the role of the Internet in mobilising protesters against tuition fee changes in England in 2010 as an example of how the Internet is becoming an important part of the political participants' toolkit. Furthermore, Bakker and de Vreese (2011) and Theocharis (2012) highlight the extensive role played by the Internet in the Obama campaign in 2008, while Van Laer and Van Aelst (2010) identify a range of 'Internet-specific' participatory acts that would not be available without the Internet (such as online petitions, email bombs or virtual sit-ins). In addition, O'Neill (2010) points out that such mobilisations and other political acts can now be performed in a manner less reliant upon traditional political institutions such 
as political parties, with consequences for the way in which citizens can engage with political institutions and actors.

The specific effect of the Internet on political participation is difficult to determine, with numerous debates ongoing about whether or not the Internet facilitates new access to political participation or if it in fact only advantages the well-resourced, and whether or not the Internet presents new participatory opportunities or merely provides a new medium through which more traditional participatory acts are performed (Theocharis, 2012; Benkler, 2006; Chadwick, 2012; Krueger, 2002; Bakker and de Vreese, 2011; Van Laer and Van Aelst, 2010; Margolic and Moreno-Riono, 2009). There is a consensus, however, that the Internet has had some impact on politics and political participation in Britain, even if the magnitude and extent of that impact is debated.

Whiteley does consider the role of the Internet and how it is used by political participants, however he does not provide a measure of the full range of participatory acts available to citizens through the Internet. Internet-based political participation is given no specific attention at all; rather the Internet is regarded as another tool through which people can participate just like a telephone or a letter. This means that no regard is given for the way in which the Internet may have changed the way in which citizens engage with politics, or to the new array of political participatory acts which are only available because of the Internet. While the impact of the Internet on politics and political participation is certainly unclear, giving this debate so little consideration creates a potential for serious error in an analysis of political and civic behaviour in modern Britain. 
Just like the impact of the Internet, the impact of globalisation is hard to identify (and in addition globalisation is difficult to define), but there is a consensus that it, too, has had a significant impact on politics and political behaviour (Norris, 2002). Globalisation has changed the relative power of the nation-state in comparison with trans-national corporations (TNCs), inter-governmental organisations (IGOs), non-governmental organisations (NGOs) and supranational bodies such as the European Union (Peterson, 1996). The nation-state is becoming an increasingly weak political actor as power shifts up to those IGOs and supranational bodies (Van Laer and Van Aelst, 2010; Norris, 2002; Peterson, 1996), down to regional and local authorities (Norris, 2002), and is given (through the privatisation of state services and responsibilities) to private corporations and not-for-profit organisations (Sloam, 2007, 2012; Norris, 2002; Marsh et al, 2007).

The impact of this shift on potential political participants has two dimensions: first, the state has been seen to 'withdraw' from their lives, leaving them more individualistic in their outlook and less likely to engage in more traditional, community based, forms of political participation (Sloam, 2007, 2012; Dalton, 2009; Norris, 2002); and second, the state's importance (whether the government, or elements of the state responsible for delivering state services) as a target of political participation has declined (Norris, 2002; Marsh et al, 2007; Sloam, 2007). Individuals are now making use of new opportunities to interact with other institutions capable of exerting influence over political outcomes (Norris, 2002; Sanford and Rose, 2007). This encourages the rise of entities such as single-issue advocacy organisations, trans-national policy networks and new social movements to represent political concerns to the bodies which have acquired the responsibility to deliver state services, expanding the choice of 
targets of political participation (Ward and de Vreese, 2011; Norris, 2002; Marsh et al, 2007).

The rise of the Internet alongside the consequences of globalisation and privatisation, therefore, has had a significant impact on political participation, even if the magnitude and consequences of that impact is unclear and contested. There is evidence that there are now means and targets of political participation beyond the sphere of acts intended only to influence state-related outcomes which are forming an increasingly prominent part of the British citizens' repertoire of political participation (Norris, 2002; Sanford and Rose, 2007; Ward and de Vreese, 2011).

While the data which underpins many of these assertions is limited (Phelps, 2012) and too often anecdotal, Dalton (2009), Sloam (2007, 2012) Talbert and Mcreal (2003) Stolle et al (2005), and Marsh et al (2007) all support Norris' assertion that even these limited indications "point more strongly towards the evolution, transformation and reinvention of civic engagement than its premature death" (2002, p.4), and that "studies of political participation focussing exclusively on conventional indicators...may seriously misinterpret evidence of an apparent civic slump" (Norris 2002, p.4).

Whiteley's conception of political participation, therefore, owing to its almost exclusive focus on behaviour designed to influence state related outcomes, as well as the limited attention paid to new forms of political participation being facilitated by the advancement of the Internet, is too restrained in light of the social changes and technological advancements in British society. He cannot be sure that he has captured a realistic and valid assessment of the political 
participation of British citizens, nor can he identify whether political participation is actually in decline, or if it is actually evolving.

For all these concerns, Whiteley's book still constitutes a significant milestone in the ongoing study of British democracy, and this comprehensive analysis will form the backbone of future research into British civil society and democratic engagement for the next decade. The trends and implications he documents of the declining engagement on the part of the British public with formal politics are still of serious concern, and his argument that the future sustainability of British democracy is at risk loses none of its potency. 


\section{Bibliography}

Almond, G.A., Verba, S. (1963) The Civic Culture: Political Attitudes and Democracy in Five Nations, London: SAGE Publications

Bakker, T.P., de Vreese, C.H. (2011) 'Good News for the Future? Young People, Internet Use, and Political Participation', Communication Research, Vol.28, pp. $451-470$

Benkler, Y. (2006) The Wealth of Networks: How Social Production Transforms Markets and Freedom, Yale, CT: Yale University Press

Bennet, W.L. (2008) Civic Life Online: Learning How Digital Media Can Engage youth, MA: MIT Press

Booth, J.A., Seligson, M.A. (1978) Political Participation in Latin America: Volume 1, Citizen and State, New York: Holmes and Meiser

Chadwick, A. (2012) 'Recent shifts in the Relationship Between the Internet and Democratic Engagement in Britain and the United States: Granularity, Informational Exuberance and Political Learning', in Andviza, E., Jessen, M., Jorba, L. eds., Digital Media and Political Engagement Worldwide: A Comparative Study, Cambridge: Cambridge University Press

Conge, P.J. (Jan. 1988), 'The Concept of Political Participation: Toward a Definition', Comparative Politics, Vol.20, No.2, pp.241-249

Dahl, R.A. (1963) Modern political Analysis, Englewood Cliffs, NJ: Prentice-Hall 
Dalton, R. (2009) The Good Citizen: How a Younger Generation is Reshaping American Politics, Washington, DC: CQ Press

Easton, D. (1965) A Framework for Political Analysis, Englewood Cliffs, NJ: Prentice-Hall, Inc.

Krueger, B.S. (2002), 'Assessing the Potential of Internet Political Participation in the United States: A Resource Approach', American politics Research, Vol.30, pp. $476-498$

Margolis, M., Moreno-Riano, G. (2009) The Prospect of Internet Democracy, Farnham: Ashgate Publishing Limited

Marsh, D., O'Toole, T., Jones, S. (2007), Young People and Politics in the UK: Apathy or Alienation?, Basingstoke: Palgrave MacMillan

Milbrath, L.W. (1965) Political Participation: How and Why do People get Involved with Politics?, Chicago: Rand McNally Company Norris, P. (2002) Democratic Phoenix: Reinventing Political Activism, New York: Cambridge University Press

Oldfield, D.M. (1996) The Right and the Righteous: The Christian Right Confronts the Republican Party, Lanham: Rowman and Littlefield Publishers Inc

O'Neill, B. (2010) 'The media's role in shaping Canadian civic and political engagement', Policy and Society, Vol.29, pp.37-5

Parry, G., Moyser, G., Day, N. (1992) Political Participation and Democracy in Britain, Cambridge: Cambridge University Press 
Pattie, C., Seyd, P., Whiteley, P. (2004) Citizenship in Britain: Values,

Participation and Democracy, Cambridge: Cambridge University Press

Peterson, V.S. (1996) 'The Politics of Identification in the Context of

Globalisation', Women's Studies International Forum, Vol.19, Nos.1/2, pp.5-15

Phelps, E. (2012) 'Understanding Electoral Turnout Among British Young People: A Review of the Literature', Parliamentary Affairs, Vol.65, pp.281-299

Salisbury, R.H. (May, 1975) 'Research on Political Participation', American Journal of Political Science, Vol.19, No.2, pp.323-341

Sanford, C., Rose, J. (2007) 'Characterising eParticipation', International Journal of Information Management, Vol.27, pp.406-421

Schonfeld, W.R. (Oct, 1975) 'The Meaning of Democratic Participation', World Politics, Vol.28, No.1, pp.134-158

Scoff, L.A. (Sept, 1975) 'Two Concepts of Political Participation', The Western Political Quarterly, Vol.28, No.3, pp.447-462

Sloam, J. (2007) 'Rebooting Democracy: Youth Participation in Politics in the UK', Parliamentary Affairs, Vol.60, No.4, pp.548-567

Sloam, J. (2012) '"Rejuvenating Democracy?" Young People and the 'Big Society' Project', Parliamentary Affairs, Vol.65, pp.90-114 
Stockemer, D., Carbonetti, B. (2010) 'Why do richer democracies survive? The non-effect of unconventional political participation', The Social Science Journal, Vol.47, pp.237-251

Stolle, D., Hoghe, M., Micheletti, M. (Jul 2005) 'Politics in the Supermarket:

Political Consumerism as a Form of Political Participation', International Political Science Review, Vol.26, No.3, pp.245-269

Theocharis, Y. (2012) 'Cuts, Tweets, Solidarity and Mobilisation: how the Internet Shaped the Student Occupations', Parliamentary Affairs, Vol.65, pp.162-194

Tolbert, C.J., McReal, R.S. (2003), 'Unravelling the Effects of the Internet on Political Participation', Political Research Quarterly, Vol.56, No.2, pp.175-185

Van Laer, J., Van Aelst, P. (2010) 'Internet and Social Movement Action Repertoires', Information, Communication and Society, pp.1-26

Verba, S. (Sept, 1967) 'Democratic Participation', Annals of the American Academy of Political and Social Science, Vol.373, pp.53-78

Verba, S., Nie, N.H., Kim, J. (1978) Participation and Political Equality: A SevenNation Comparison, Cambridge: Cambridge University Press

Verba, S., Nie, N.H. (1972) Participation in America: Political Democracy and Social Equality, New York: Harper and Row 
Verba, S., Schlozman, K.L., Brady, H.E. (1995) Voice and Equality: Civic Voluntarism in American Politics, Cambridge: Harvard University Press

Wattenberg, M.P. (2002) Where have all the voters gone?, London: Harvard University Press

Ward, J., de Vreese, C. (2011) ' Political consumerism, young citizens and the Internet', Media Culture Society, Vol.33, pp.399-413 